\title{
Correction to: A novel double-layered polymeric nanofiber-based dressing with controlled drug delivery for pain management in burn wounds
}

\author{
Sharjeel Abid ${ }^{1}$ (I) - Tanveer Hussain ${ }^{1}$ - Ahsan Nazir ${ }^{1}$ - Abdul Zahir ${ }^{1}$. \\ Nabyl Khenoussi ${ }^{2}$
}

Published online: 11 January 2021

(c) Springer-Verlag GmbH Germany, part of Springer Nature 2020

\section{Correction to: Polymer Bulletin (2019) 76:6387-6411 https://doi.org/10.1007/s00289-019-02727-w}

The original version of this article inadvertently contained mistake.

In the article, the term "swear" should actually be "severe".

Publisher's Note Springer Nature remains neutral with regard to jurisdictional claims in published maps and institutional affiliations.

The original article can be found online at https://doi.org/10.1007/s00289-019-02727-w.

Sharjeel Abid

m.sharjeel.abid@gmail.com

1 Electrospun Materials and Polymeric Membranes Research Group (EMPMRG), National Textile University, Faisalabad, Pakistan

2 Laboratoire de Physique et Mécanique Textiles (LPMT), Electrospinning Group, Université de Haute-Alsace, Mulhouse, France 